eISSN: 2659-6482

DOI: https://doi.org/10.14201/pmrt.21746

\title{
LA ESPAÑA DE LOS AÑOS 70 EN LA TELEVISIÓN CONTEMPORÁNEA. RECUERDOS DE UNA SOCIEDAD EN CONFLICTO A TRAVÉS DE LA MÚSICA EN CUÉNTAME CÓMO PASÓ
}

\section{The Spain of the 70s in contemporary television. Memories of a society in conflict through music in Cuéntame cómo pasó}

\author{
Judith Helvia GARCÍA MARTÍN \\ Universidad de Salamanca \\ helvia@usal.es
}

RESUMEN: De entre todas las series de Televisión Española, Cuéntame cómo pasó es la más longeva. Con la premisa de mostrar de manera costumbrista la vida de una familia española que, como tantas otras, emigra del campo a la ciudad en algún momento de los años 50, entrelaza acontecimientos reales de la historia de España acaecidos entre 1968 y (por ahora) 1991 con la vida cotidiana de los Alcántara. Dadas las características de la situación sociopolítica que atraviesa el país durante estos años, uno de los principales motores de las diversas líneas argumentales será el establecimiento de conflictos entre elementos opuestos, tratando de que los personajes hallen un punto de conciliación. De este modo, habrá una constante pugna entre lo urbano y lo rural, lo festivo y lo ritual, lo político y lo frívolo, lo moderno y lo tradicional. En este artículo veremos cómo las elecciones de música diegética, realizadas desde la perspectiva del siglo XXI, dibujan a través del paisaje musical estas dicotomías de la España de los años 70, década a la que nos circunscribimos por ser con la que la serie muestra un espectro más amplio de estilos.

Palabras clave: Cuéntame cómo pasó; series de televisión; música diegética; España; años 70. 
ABSTRACT: Among all the Spanish TV series, Cuéntame cómo pasó is the longest one. With the premise of showing in a traditional way the life of a Spanish family that, like so many others, migrates from the countryside to the city at some time in the 50s, intertwines real events of Spanish history that occurred between 1968 and (for now) 1991 with the daily life of the Alcántaras. Given the characteristics of the socio-political situation of the country during these years, one of the main engines of the various plot lines will be the establishment of conflicts between opposing elements, trying to make the characters finding a point of conciliation. In this way, there will be a constant struggle between urban and rural areas, festive and ritual contexts, political and frivolous manifestations, modern and traditional generations. In this article we will show how the choices of diegetic music, made from the perspective of the 21st century, illustrate these dichotomies through the musical landscape of the Spain of the 70s, decade to which we circumbscribe this article for being the one with which the series shows a wider spectrum of styles.

Key words: Cuéntame cómo pasó; TV series; diegetic music; Spain; 70s.

\section{CUÉNTAME CÓMO LLEGÓ}

La serie más longeva de Televisión Española, Cuéntame cómo pasó, ha sido hasta la creación de recientes producciones con mayor impacto internacional uno de los programas con mayor incidencia del panorama televisivo nacional (Domínguez Lázaro, 2010). Lo es hasta tal punto que ha constituido un elemento más para la construcción del imaginario español (Mateos, 2014). La premisa de este producto televisivo es, en principio, muy prosaica: muestra la vida cotidiana de la familia Alcántara a partir de 1968, habiendo emigrado del empobrecido campo manchego a Madrid en algún momento de los años 50. Así pues, cabe preguntarse cuál ha sido la clave de su éxito y qué ha mantenido su renovación durante diecinueve años.

Una de las primeras cuestiones a plantearse es el grupo poblacional al que se dirige. Su audiencia es la de la televisión generalista española, «integrada por una leve mayoría de mujeres y una media de edad dominante superior a los 45 años» (Rueda y Guerra, 2009: 402). Según el estudio de Diego, Etayo y Pardo (2011: 80), el programa es preferentemente seguido por espectadores españoles mayores de 35, aunque con mayor incidencia entre los 65 y los 74 años (siempre hablamos de edades cumplidas en el momento del estudio). Ocurre, además, que «cuanto mayor es la preferencia por la serie, menor es el nivel de educación». Esta conexión 
resulta lógica puesto que, a mayor edad, encontraremos un menor porcentaje de población que haya accedido a estudios superiores en su juventud.

A pesar de este perfil de edad, que parece indicar una preferencia en aquellos telespectadores que vivieron en primera persona la época en la que transcurre la acción, lo cierto es que la serie tiene potencial para trascender a otros colectivos gracias a las cuatro generaciones representadas que, a su vez, conectan con los valores y actitudes de los espectadores actuales (Castillo, Simelio y Ruiz, 2012). Efectivamente, en cada uno de los estereotipos representados (descritos también por Rueda y Guerra, 2009) el espectador no solo se reconoce a sí mismo, sino también a sus familiares. Además, como indica Estrada (2004: 548), a la generación más joven de españoles que sabe poco de la Guerra Civil y la dictadura les interesa la serie por la época que vivieron sus padres. Así, las dos abuelas, Herminia y Pura, ambas viudas y nacidas alrededor de 1900, son los baluartes de la tradición, las confidentes y las transmisoras de sabiduría. Les siguen Antonio y Mercedes, que ya han cumplido los 40; son trabajadores y emigrantes a la ciudad, padres de familia atrapados en el dilema que les supone seguir aferrados a las tradiciones que aprendieron de niños en el pueblo o adaptarse a los rápidos cambios que se suceden en la ciudad a la que se vieron obligados a marcharse. Estos, sin embargo, son muy bienvenidos por sus hijos, Inés y Toni, de 20 años y criados en la urbe; y Carlos, que a sus 10 años solo ha conocido la ciudad y sus comodidades, y en su descubrimiento del mundo se verá reflejado todo el público infantil.

Este amplio perfil de telespectadores, unido al mimo con el que la cadena ha programado la serie en una franja estable en horario de prime-time, ha contribuido a que su éxito de público haya sido considerable, convirtiéndola en ganadora en la guerra de audiencias (Torrado y Castelo, 2005), lo cual ha justificado su renovación temporada tras temporada aun cuando parece que la fórmula lleva tiempo agotada.

Esta conexión en base a grupo de edad, sexo o procedencia social se ve además reforzada por los conflictos que articulan los hilos argumentales, fácilmente conectables con cuestiones del presente. Parece que los Alcántara se encuentran implicados en todos los acontecimientos relevantes del tardofranquismo y la Transición. Al margen de la verosimilitud (o falta de ella) que supone verles inmersos en toda suerte de eventos históricos gracias al uso de imágenes de archivo combinadas con chroma key (Brémard, 2015: 88), muchas de las problemáticas abordadas encontrarán resonancia en los acontecimientos presentes. Como indican Rueda y Guerra (2009: 404), esta serie constituye «un texto emblemático donde poder percibir las relaciones de afinidad entre tiempo del autor y del receptor», ya que da pie a trasladar a la ficción histórica aspectos que pueden leerse desde el presente, como la crisis inmobiliaria, el debate sobre la Memoria Histórica o la violencia machista. Sin embargo, esta mirada es, como nos recuerda Estrada (2004), un tanto amable y edulcorada, lo que incluye este programa dentro del 
«pacto del olvido» de la transición democrática y, en última instancia, hace que su visionado sea agradable para un público amplio.

\section{CUÉNTAME CÓMO SONÓ}

Cuéntame cómo pasó ha sido abordada desde diferentes puntos de vista. Sin embargo, no se ha analizado qué papel ha jugado la música en su construcción del mensaje sobre la Transición. Para ello, en este artículo queremos bucear en el uso de la música diegética como elemento de representación de los conflictos y contradicciones propios de un momento de cambio tan grande como fue la España de los años 70. Para ello, veremos con qué repertorios se ilustran no solo las luchas generacionales, uno de los pilares argumentales más evidentes, sino también las pugnas entre elementos que buscan conciliación, como lo urbano y lo rural, lo festivo y lo ritual, lo político y lo frívolo, lo moderno y lo tradicional. Estos extremos, que cuando son tratados aparecen al principio como irreconciliables, acaban hallando al final un punto de encuentro, buscando siempre un final feliz con el que la audiencia se sienta cómoda. Esto conecta con la afirmación de Estrada (2004: 562), quien nos recuerda que esta serie «al perpetuar la conciliación que caracterizó el proceso de transición, se solidariza con los sectores sociales y políticos que no consideran necesario revisar la Transición». Por lo tanto, veremos cómo la música preexistente y diegética ilustra todos estos diálogos.

Para ello hemos realizado un vaciado de músicas utilizadas de manera diegética en las primeras 13 temporadas (233 capítulos), parándonos al llegar 1981. Los motivos que nos llevan a establecer este marco son, por un lado, la imposibilidad de tratar en la extensión de este artículo los (hasta la fecha) 370 capítulos emitidos. Por ello hemos considerado más eficaz para nuestro objetivo seleccionar aquellas temporadas que abarcan un ámbito cronológico interno de la serie en el que los citados conflictos están más presentes: los años 70. Las tramas posteriores se centran más en el desarrollo personal de los personajes (la relación de pareja entre Antonio y Mercedes, la profesión de actriz de Inés, el encarcelamiento de Carlos...). Sin embargo, durante la década de los 70 están mucho más sujetas a acontecimientos políticos y sociales del momento (las revueltas estudiantiles, la liberación de la mujer, los presos políticos, la llegada de la democracia...), y su vinculación con todas las dicotomías a las que antes me he referido hace que la variedad de estilos insertados sea mucho mayor. Estos van a pertenecer mayoritariamente a diversas músicas populares, desde la zarzuela y la copla, pasando por bailes como el bolero, el cha-cha-chá o el pasodoble, hasta otros estilos más contemporáneos al tiempo interno de la serie, como el pop o la canción de autor. Por otro lado, la mayoría de estas temporadas cuentan con Mario de Benito como responsable de la banda sonora, lo que hace que los criterios a la hora de elegir 
y tratar la música preexistente sean homogéneos. Cada uno de los ejemplos que se adjuntan en el anexo se citará entre paréntesis en el cuerpo del texto con su correspondiente número.

De este vaciado, y dado que lo que buscamos es el refuerzo de conceptos a través de determinados repertorios, hemos excluido las músicas diegéticas cuya función es más ambientadora que portadora de un contenido significativo. En esta categoría incluiríamos las escuchas ocasionales de la radio como elemento que acompaña a las tareas cotidianas, momentos que además se caracterizan por dejar este elemento sonoro en un tercer plano, lo que hace difícilmente reconocible la pieza seleccionada.

De igual modo, hemos excluido del análisis (aunque añadimos los ejemplos en los anexos) la inserción diegética de música clásica, ya que este repertorio no se usa para ilustrar ninguno de los conflictos representativos de la España de la Transición antes enumerados. Además, queda excluido de los discos recopilatorios comercializados, así como de los dos especiales sobre música emitidos a lo largo de estas 13 temporadas (capítulos 118 y 234). En cambio su uso parece restringirse a reforzar significados estereotipados, como las diferencias de clase en la trama de Mercedes y Bárbara (10). Otros usos más particulares serían como elemento encubridor de las actividades ilícitas de Toni, como sus reuniones con la Liga Comunista Revolucionaria (9). O como hilo conductor de la relación de Antonio con Elisa, una mujer culta que le abre un mundo musical desconocido para él (1-8), ante lo cual su familia reacciona extrañada porque de repente «escuchaba una música aburridísima que en nada se parecía a la de Massiel, Los Bravos o Karina» (capítulo 83, 00:02:09).

Como era de esperar, la música coetánea (diegética o no) al momento representado es un recurso relevante en este diálogo con el espectador actual construido desde la nostalgia. Como hemos señalado, una gran parte de los seguidores del programa vivió, de niño o adolescente, el tiempo interno de la serie, por lo que resulta sencillo comunicarse con ellos afectivamente mediante la música presente en su socialización primaria (Piñeiro-Otero, 2018: 103), es decir, la que formó parte de sus vidas reales de forma simultánea a los años representados en la ficción. Dicho de otro modo, es la música que constituye su identidad sonora, su biografía musical, teniendo en cuenta que aquella que está presente durante los años del desarrollo de nuestra personalidad (adolescencia y primera juventud) queda especialmente grabada en el recuerdo por su importante carga afectiva.

Mario de Benito, responsable de la banda sonora entre 2001 y 2010, comenta en una entrevista que en los primeros momentos esta serie «no llevaba mucha música porque querían darle un tono muy veraz, natural» (López, 2016: 373). Entendemos que ese «no llevar mucha música» se refiere a la original y extradiegética. Este «tono veraz», por tanto, no solo viene dado por la dosificación de esta última, 
sino también por la inclusión de un repertorio caracterizador de personajes (y, añadimos, ideologías, conceptos, eventos...) que aparece en momentos cotidianos. Un repertorio que es preexistente, pero relativamente reciente, lo que hace que los derechos de autor sigan vigentes y el presupuesto para música de esta serie sea elevado. La forma de insertar estas canciones resulta ser una versión musical del recurso narrativo visual utilizado al incluir a los personajes ficticios en documentos de archivo a través del chroma key. Así lo explica De Benito (2016: 374):

Los directores hablaban conmigo. Elegían un tema y hacíamos una versión de ese tema. Por ejemplo, con «La chica ye-ye». Se hacía alguna pincelada de ráfaga sobre La chica ye-ye y quedaba precioso. Se compraba por ejemplo un minuto y medio de la melodía. Y se ponía un minuto de la canción y el otro medio minuto era una versión.

Piñeiro-Otero (2018: 99) señala que en las series de ambientación histórica los temas preexistentes suelen ser «música de pantalla» (diegética), mientras que los originales se dejan como «música de foso» (extradiegética). Sin embargo, en el caso de Cuéntame cómo pasó la inclusión de música preexistente con el objetivo de caracterizar personajes, situaciones o para otorgar esa veracidad de la que hablaba De Benito pertenece a ambas categorías. Aquí nos centraremos en la primera.

Como hemos venido indicando, la música diegética se ha utilizado para ilustrar diversos conceptos, a menudo en conflicto entre sí. Debido al enfoque costumbrista de la serie, buena parte de ellos se dan en el ámbito doméstico. De hecho, Oller-Alonso (2012: 134) estima que cerca de tres cuartas partes de la historia transcurren en las casas familiares, mientras que el resto lo hace en los entornos sociales y profesionales de los protagonistas (calles, parques, bares, cafés...). Sin embargo, la música nos va a transmitir una variedad de espacios mucho mayor. Aunque aquí vamos a establecer categorías en su utilización conforme a las dualidades que representa, estas no deben verse como compartimentos estancos, ya que un determinado repertorio puede al mismo tiempo ser político pero ser usado en un contexto ritual; o ser moderno y aparecer en un entorno tradicional; o que algo propio de la generación de Antonio y Mercedes sea adoptado por sus hijos. Por lo tanto, los siguientes apartados deben entenderse siempre como vasos comunicantes entre los que fluyen trasvases constantes.

\section{LOS ABUELOS, LOS PADRES, LOS NIETOS}

Como es habitual en las series intergeneracionales, habrá un estilo musical diferente vinculado a cada grupo de edad de los personajes: aquellos que nacen hacia 1900, los que lo hacen en 1930, en 1950 y por fin en 1960. Y ese repertorio va a estar casi siempre asociado a lo que los personajes escuchaban en su juventud 
que, como indicábamos antes, es la época en la que se consolida la personalidad y en la que la música más se adhiere a nuestros recuerdos, vinculada fuertemente a la afectividad.

Por un lado, nos encontramos con las más veteranas, las abuelas Herminia y Pura, nacidas en las postrimerías del siglo XIX. Aficionadas a escuchar en la radio las radionovelas y los concursos, se van a manifestar amantes de la copla y los pasodobles, pero también de tangos y boleros. Esto se debe a que partir de los años 40 la música escénica (zarzuela y derivados), de la mano de compositores como Jacinto Guerrero o Francisco Alonso, comienza a llenarse de ritmos tropicales de sambas, rumbas, congas y, por supuesto, boleros y danzones como consecuencia del éxito de las películas de Carmen Miranda (González Lapuente, 2013: 487). Estos repertorios de baile se van a observar en capítulos autoconclusivos con protagonistas pertenecientes a la generación de las abuelas, como el relativo al tío Gerardo de Argentina (23); o aquel en el que conocemos a la novia de juventud de Cervan (16). Pero sobre todo se manifiestan en tramas más extensas, como la relativa al baile parroquial organizado por Eugenio. Consciente de la necesidad de las personas mayores de tener un entretenimiento entre iguales, les dará la oportunidad de reunirse en el salón parroquial donde bailarán boleros y cha-chachás de Antonio Machín y pasodobles conocidos por ser «números bomba» de zarzuelas y revistas $(19-22,25)$. Por otro lado, este recopilatorio también va a utilizarse para caracterizar a personajes que son de la generación de Toni e Inés, pero cuyo estilo de vida es conservador $(24,35)$.

La siguiente generación, Antonio y Mercedes, aún no se halla inmersa en el mundo de las modas musicales, ni por edad ni por gustos, por lo que conserva los de la generación de sus madres. Esto se muestra en la trama en la que Mercedes acude a clases de baile, en las que aprenderá a bailar el pasodoble, el bolero y el cha-cha-chá (40-43). En varias ocasiones se señala que a Antonio le gustan los boleros y el flamenco, pero también los pasodobles y la zarzuela $(29,34)$ pues, como indica González Lapuente, la zarzuela «estaba viva en las clases popular y media... se tarareaba en los años cuarenta en los despachos, a la hora del asueto» (2012: 483). Aun así, a sus escenas de pareja se incorporan otros repertorios más modernos, como las baladas de Armando Manzanero o el pop de Patty Pravo $(14,18)$. El bagaje musical de la pareja se recoge en el disco Cuéntame cómo pasó, Vol. 3. Las canciones de Merche y Antonio (2002).

El gran cambio se produce con los hijos, Inés y Toni. A sus 20 años, forman ya parte de esa generación de jóvenes que, tras la II Guerra Mundial, pueden permitirse estudiar en vez de trabajar y disponen a la vez de tiempo libre y dinero, lo que les convierte en un apetitoso mercado para la incipiente industria musical que ahora llega a todos los rincones gracias a medios como la radio o la televisión. Por eso, son el público perfecto para los grupos de música comercial que encarnan 
la dualidad pop-rock, que comienzan a surgir ahora en España y que imitan las boy bands siguiendo la estela de los Beatles y los Rolling Stones $(11,13,15)$. Este repertorio comercial se verá también a través de otros personajes de su edad, como Pili o Françoise, quienes se declaran seguidoras de Johnny Hallyday, Benoît Blue Boy o Patrick Verbeke (39). Estos gustos van a ser compartidos en un primer momento por los dos hermanos mayores. Sin embargo, como explicaremos más adelante, esto cambiará a medida que definan su personalidad.

Por su parte, Carlos en su infancia será afín a los artistas pop producidos por la industria musical y la televisión como Marisol o las cantantes de Eurovisión $(12,17,28,30)$ para, más adelante, adoptar las preferencias de su modelo masculino más cercano, Toni y, por último, definir sus gustos más personales durante la Movida madrileña.

En ocasiones, encontramos historias que implican a personajes de generaciones diferentes, como la relación amorosa de Toni y Clara, y los gustos musicales entran en conflicto. En esta situación, la pareja baila «Dos Gardenias para ti». A pesar de que Clara dice que se sigue bailando en los pueblos, Toni se siente incómodo con esta música (26). Finalmente, acabarán encontrando un punto de encuentro con Edith Piaf (27). Estos desajustes entre edad y repertorio se pueden ver también cuando personajes mayores, como Don Pablo, Antonio y Miguel, acuden a clubs nocturnos donde su edad no encaja (31-33, 36-38).

\section{LO URBANO Y LO RURAL}

Aunque la residencia de la familia Alcántara está en el ficticio barrio madrileño de San Genaro, el espíritu de sus miembros más mayores (abuelas y padres) se debate entre las raíces rurales de las que proceden y el nuevo entorno urbano al que deben adaptarse. Son la encarnación de lo acaecido a tantas otras familias de su época. Hasta los años cincuenta las migraciones eran de carácter temporal debido al peso que ocupaba el sector primario en la economía española (Romero Valiente, 2003: 215). Según esto, primero emigra Antonio, dejando a Mercedes, Inés y Toni en el también irreal pueblo de Sagrillas, a los que va a ver cada cierto tiempo. Una vez se mecaniza el sector primario como consecuencia del nuevo contexto desarrollista, estas migraciones se convierten en permanentes hacia la periferia de los centros industriales y, por eso, tras un tiempo la familia se reunirá definitivamente en San Genaro, que encarna un barrio de aluvión.

Durante las tres primeras temporadas la acción tiene lugar exclusivamente en la ciudad, aunque el concepto de «Sagrillas» siempre está presente para el espectador de forma abstracta como el pueblo del que tuvieron que escapar para progresar. Sin embargo, la muerte de la abuela Pura supondrá un punto de inflexión, ya que hará que vuelvan a la villa para su funeral y reconecten con sus orígenes. A partir 
de entonces, retornarán cada vez con más frecuencia y la localidad se convertirá en un lugar de evasión y de reencuentro con ellos mismos: su lugar de vacaciones; el escondite para huir de persecuciones políticas; el entorno ideal para rehabilitarse de adicciones; el lugar donde apartarse del mundanal ruido urbano, en definitiva.

Puesto que las temporadas que pasan allí suelen coincidir con las fiestas navideñas, Semana Santa y con las vacaciones de verano, vamos a encontrar varios capítulos en los que se llevan a cabo diversas celebraciones que tienen que ver con el ciclo vital (los Mayos), con las canciones de trabajo (matanza y vendimia) y con las festividades religiosas (romerías), todo ello acompañado de las correspondientes verbenas. Son celebraciones que siempre tienen lugar en el entorno rural y que adquieren un tinte «ancestral» al ser acompañadas de un repertorio tradicional que se presenta por oposición a lo urbano/moderno/político (categorías que veremos más adelante).

«Lo rural» va a manifestarse musicalmente a través de distintas vías. Por una parte, como un entorno extraño cuyas costumbres se han conservado al margen del mundo exterior y deben ser explicadas. Por otro lado, con el tiempo estas tradiciones «sin contaminar» se verán «pervertidas» por otro tipo de repertorio. También como algo que pervive a través de las canciones infantiles, que no solo cantan niños, sino también personas que han vivido la mayor parte de su vida en el pueblo y aún las conservan en su memoria. Por último, lo rural/tradicional vendrá de la mano de las canciones de trabajo y de cuna.

Como decíamos, se presenta el espacio rural como una especie de cápsula del tiempo, acorde con esa concepción clásica del folklore como un «depósito musical campesino en zonas cuya población se había movido escasamente» (Barce, 1987: 151). Su repertorio parece no haber salido de esa burbuja y, por eso, cuando los personajes vuelven al pueblo y lo escuchan deben recordar para qué sirve y, de paso, se lo explican también al espectador contemporáneo (García Martín, 2016: 129). Esto ocurre de manera muy evidente en dos ocasiones. En una de ellas Antonio y Toni pasean por el pueblo y se encuentran el sorteo de mozos en la festividad de los Mayos. El padre debe explicar a su hijo, que no ha vuelto por allí desde muy pequeño, que esa era la mejor forma de ennoviarse (45). Ante el desdén de Toni, su padre le recuerda que «de la tradición solo se ríen los tontos». En el segundo ejemplo, Sagrillas atraviesa una larga sequía, y los habitantes deciden sacar a la Virgen en procesión para pedir lluvia cantando la «Rogativa a la Virgen de Turruchel» (52), cuyo texto completo puede consultarse en García Lanciano (2004: 27). La escena es presenciada por Antonio y Miguel. El último, que lleva muchos años en Francia, no recuerda el porqué de la procesión, y es de nuevo Antonio quien debe explicárselo: «Esto son la procesión de las rogativas, para pedirle a la Virgen que llueva, Miguel, ¿no te acuerdas?». Guillén Navarro (2004: 19) clasifica las rogativas como música religiosa del ciclo de primavera, pero la 
escena transcurre en diciembre. Estaría fuera de su momento, pero conserva su función: invocar la protección de la Virgen o de un santo patrón frente a la pérdida de cosechas por la escasez de lluvia.

Sin embargo, este lugar remoto que nos parece Sagrillas la primera vez que lo conocemos sufrirá cambios con las sucesivas vueltas de los Alcántara al pueblo. Y esto se manifestará musicalmente con la inclusión de nuevos repertorios. Parece como si en ese proceso de ida y vuelta en el que las familias emigradas a las ciudades vuelven a hacer suyo el pueblo como seña de identidad, trajeran a su lugar de origen lo aprendido y adoptado (musicalmente) en su lugar de acogida. Y así, volviendo a la cita de Barce y a la concepción romántica del folklore, ese repertorio tradicional que se había fijado y cristalizado «sufre la agresión del exterior (músicas foráneas, formas musicales modernas) que pone en peligro la pureza de ese acervo» (1987: 151). Esto se observa principalmente en las romerías y verbenas de las diferentes festividades, que en un principio amenizan agrupaciones locales de dulzaina y tamboril con jotas, seguidillas y bailes «agarraos» $(46,53)$. Esto será sustituido más adelante por las pequeñas orquestas festivas itinerantes (batería, guitarra, teclado, saxofón y cantante), en las que conviven números heredados de la copla y la zarzuela para los más mayores con un repertorio de bailes más modernos (como el mambo) y baladas $(55-57,60)$.

Lo rural se manifiesta también a través del repertorio infantil presentado de diversas formas. Fuera del muestrario del anexo, por ser música extradiegética, quedarían ejemplos en los que se versionan canciones de juegos, como «Antón Pirulero» (capítulo 54, 00:24:45), «Borriquito como tú» (capítulo 79, 01:09:08) o «Vamos a contar Mentiras» (capítulo 83, 00:20:44). Pero lo habitual es que estas canciones se interpreten por los niños mientras juegan $(49,54)$ o por personajes que han pasado la mayor parte de su vida en el pueblo y que lo interpretan como canciones de cuna o como divertimento y acompañamiento de tareas cotidianas $(44,47,48,58,59)$.

Y precisamente las canciones de trabajo surgen también en una especie de cuadros costumbristas (la matanza, la vendimia...) en los que asoma esa idea de la aldea idílica que muestra un reflejo arcádico de lo rural (Gómez, 2004: 985), en la que la sociedad campesina vive en armonía guardando celosamente su música que saca a relucir mientras realiza alegremente sus quehaceres diarios (51). Por eso, cuando viajan a esta «Arcadia» moderna se sienten libres (50). Merece la pena citar aquí dos ejemplos que se salen del marco cronológico que nos hemos impuesto, en los que efectivamente ese desempeño idealizado y edulcorado de las labores del sector primario se acompaña de repertorio tradicional como canciones de trabajo. Ambas ocasiones vienen a cuenta del establecimiento de unas viñas y bodega por parte de los Alcántara. En la primera (capítulo 245), se encuentran pisando la uva mientras cantan «A la Mancha manchega», recogida en el disco «Un camino 
a la Mancha/Siembra». Madrid: Discos Columbia S.A., 1980 (García Lanciano, 2004: 62). En la segunda, la familia vendimia al son de la versión que el grupo Jarcha hizo en su disco El rayo que no cesa (2010) del coro en forma de seguidilla que Miguel Hernández incluye en Los hijos de la piedra (acto II, escena I), también conocido como «Canción de los vendimiadores».

\section{LO RITUAL Y LO FESTIVO}

En muchas ocasiones ambos conceptos van de la mano, por ejemplo, cuando se trata de sacramentos que marcaban momentos relevantes en la vida de las personas (bautizos, comuniones y bodas). Pero, incluso en estos casos, se establece una clara separación espacial y musical entre el rito en sí y la fiesta posterior, que incluye repertorios ligeros que podemos encontrar en cualquier otra celebración no vinculada a lo religioso.

En el contexto eclesiástico, plasmado casi exclusivamente a través de las prácticas en la parroquia del barrio de San Genaro (y a veces mediante procesiones en Semana Santa: 93, 94), veremos en un entorno urbano los cambios en los hábitos musicales traídos por el Concilio Vaticano II. En primer lugar aparece un repertorio disperso que refleja de alguna forma las prácticas preconciliares o que, al menos, intenta transmitir la idea de tradición. Este incluye grabaciones de música para órgano, música clásica y piezas con texto en latín, reservadas para celebraciones eucarísticas especiales, como la misa de Navidad $(61,71,72,79,80)$. Sin embargo, a medida que avanzan los capítulos y, sobre todo, cuando entra en la dirección de la parroquia la figura del «cura progre» encarnada en Eugenio, veremos intentos de renovación. A partir de entonces se incluirá una amalgama procedente de cancioneros litúrgicos pre- y postconciliares, contrafacta de músicas del movimiento hippie y el pop y canciones-protesta de calado político menor $(62,65,66,75,82,93,94)$. Estas se suelen incluir en secciones del propio de la misa, aunque en ocasiones emplean textos del ordinario pero de forma libre, como el llamado "Santo de los Beatles», que no incluye la alabanza «Hosanna en el cielo» (Cruz, 2012: 119-126). La serie emplea correctamente estos repertorios, y así escuchamos en coros parroquiales acompañados de guitarra «La Juventud Tiene Razón» y «Qué Alegría cuando me Dijeron» en la entrada, «A la Huella a la Huella» en el interleccional, « $i \mathrm{Oh}$, Pecador!» en el final de la misa o el «Santo de los Beatles» en el Santo.

Cuando a la celebración religiosa le sigue una fiesta popular (bodas, bautizos o comuniones), esta se amenizará con un repertorio «de amplio espectro», que incluye pasodobles como «Paquito el Chocolatero», «España Cañí», «Tres Veces Guapa...» $(64,68,74,89)$ y valses $(73)$. Ya entrados en los años 70 , hará aparición en estas reuniones el pop más comercial de Georgie Dann, Rumba Tres, Los Mismos... $(92,95,96)$. Estas colecciones, junto con los pasodobles y otros bailes 
como el bolero, amenizarán también todo tipo de reuniones intergeneracionales como cumpleaños o celebraciones de Nochevieja $(63,76,87,88,97)$. Los guateques, la reunión festiva adolescente por excelencia, van ser a su vez los transmisores de los gustos musicales más modernos y estilos más variados, desde Georgie Dann, pasando por Los Sírex, Bruno Lomas, Paul Anka o Los Brincos, entre muchos otros $(67,69,70,77,78,83-86,90,91)$. A todos estos ejemplos expuestos en el anexo, habría que sumar los recogidos en el capítulo especial n. ${ }^{\circ} 118$ «Yesterday», que hace un resumen de todos los estilos de moda en los años 70.

Cabe destacar la inserción de un baile ceremonial como el aurresku (81) en el convite de un casamiento, ejemplo que podríamos haber incluido en la categoría «Lo político y lo frívolo» debido al contexto de la trama del capítulo. El día en que ETA comete un atentado en un cuartel de la Guardia Civil, Toni y Juana acuden a una boda en el País Vasco entre cuyos invitados hay terroristas reconocidos, y donde se homenajea a los novios con el aurresku. No parece casualidad que en la primavera de 2007 la banda terrorista diera por finalizada una tregua de 14 meses, y que este episodio se emitiera poco después aprovechando que la cronología interna de la serie pasaba por «los años de plomo».

\section{LO TRADICIONAL Y LO MODERNO}

Durante las primeras temporadas, las tensiones entre tradición y modernidad va a ser una constante en la construcción de los personajes y el desarrollo de los acontecimientos. Y si la representación musical de la modernidad va a estar tanto en las músicas populares urbanas como en la canción de autor, la tradición se verá reflejada también en dos vertientes: la música de tradición oral y la derivada de la escena.

Puesto que de la música tradicional hemos hablado anteriormente, empleada sobre todo para referirse al medio rural, y que la canción de autor se utiliza para aludir a lo político (y, por lo tanto, lo abordaremos más adelante), aquí nos detendremos más en la contraposición de otros dos repertorios como representación de lo moderno y lo tradicional: respectivamente, las músicas populares urbanas y la música escénica española derivada de la zarzuela, la copla y la revista. No obstante, parece relevante adelantar aquí que la canción protesta y la música escénica son dos estilos que también van a contraponerse, ya que se asociarán a personajes pertenecientes a dos colectivos enfrentados ideológicamente que irán acercando posiciones al llegar la democracia: por un lado, la izquierda política clandestina que se manifiesta a través de los cantautores; por otra parte, el colectivo que, o bien era afín al régimen franquista, o al menos no protestaba abiertamente contra él, muestra entre sus gustos musicales géneros promovidos por el aparato propagandístico como símbolos nacionales. Por eso, una vez establecida la democracia y redactada la Constitución de 1978 con concesiones de una y otra parte, las músicas 
que les identificaban también se desvanecerán en la serie, y solo reaparecerán para acompañar a personajes nostálgicos del régimen.

El repertorio procedente de la música escénica (zarzuela y copla) se escuchará principalmente en entornos donde se muevan personajes afectos al régimen franquista, como, por ejemplo, la casa o la empresa de Don Pablo $(105,109)$, donde los pasodobles amenizan como si fueran canciones patrióticas (García Martín, 2015: 164). También en eventos que constituyan entretenimientos tradicionales como las corridas de toros $(127,130)$. La copla, por su parte, se hace presente sobre todo a través de los programas de televisión que ve la familia, ya sean actuaciones televisadas o bien mediante la aparición de tonadilleras en la publicidad $(100,144)$. Por último, la revista será el entretenimiento que proporcione un «placer culpable» a consumidores de ocio sin pretensiones, normalmente de la generación de Antonio y Mercedes (113). Es, además, un género asimilado por los protagonistas después de llegar a la ciudad y asociado a los vicios de la misma, ya que tras la Guerra Civil Serrano Súñer prohíbe en 1939 las revistas en pueblos de menos de 40000 habitantes (González Lapuente, 2012: 485), a los cuales evidentemente la ficticia Sagrillas no llegaría. Por eso va a ser un espectáculo que genera emociones contradictorias en los protagonistas, que, por un lado, aceptan el placer que les produce disfrutar de un espectáculo frívolo, pero, por otro, no ven con buenos ojos que personas cercanas a la familia se relacionen con él. Por este motivo, cuando Inés manifiesta su decisión de dedicarse al teatro sus padres reciben la noticia con un disgusto mayúsculo, convencidos de que todas las actrices están destinadas a ser vedettes o chicas de conjunto.

La modernidad, por su parte, va a venir de la mano de estilos y contextos muy variados. La prima Françoise será el elemento exótico en los primeros años 70 que nos hable de Sylvie Vartan, Benoît Blue Boy o Patrick Verbeke (39, 102). Su cosmopolitismo será retomado por el personaje de Karina que, tras su estancia en el Reino Unido, traerá aires de soul y diferentes subgéneros del rock (148-150, 161, 162). La televisión, tratando de transmitir una imagen aperturista en los últimos años del Franquismo, emite actuaciones de Julio Iglesias, Georgie Dann, Marisol o Raffaella Carrà (104, 108, 111, 117, 132, 133, 152, 164). Inés y su evolución constante nos irán descubriendo nuevos mundos y, a medida que lo haga ella, pasaremos por diversos binomios que nos muestran la introducción de estilos muy variados en el panorama musical español: el mundo del teatro + jazz y chanson; el mundo del cine + pop; su relación con Mike + pop británico; su adherencia al movimiento hippie + pop psicodélico y canción folk $(96,107,110$, $112,125,126,136-140,145,146)$. Por el contrario su amiga Pili, más conformista, gustará de un repertorio más limitado y comercial, como Los Canarios, Los Bravos o Camilo Sesto $(123,124,141-143)$. Carlos y sus relaciones con Karina y Julia nos mostrarán un amplio espectro de baladas $(147,151,153,154,156,169,170)$. Lo 
que escuchan los jóvenes en sus reuniones privadas también será un buen indicativo de los gustos adolescentes de los 70, ya que se trata de entornos relajados donde ellos eligen el repertorio $(101,103,106,120,128,129,155)$. Aunque una de las principales vías para mostrar la modernidad musical comercial van a ser las numerosas ocasiones en las que los personajes salen a locales de ocio, cuya variada tipología incluye discotecas, cantinas, bares y futbolines $(98,115,118,119,121$, 122, 165-168, 171-173). Sin embargo, también en estos espacios se observarán diferencias generacionales, por lo que en contextos como salones de baile de hoteles y otros locales en los que el público sea mayor los protagonistas serán Nino Bravo, la rumba y el bolero $(131,157,158,160,163,174,175)$. Cuando una canción esté desfasada, así lo harán notar los personajes, como les ocurre a Toni y sus amigos con «La Yenka» o «Si yo Tuviera una Escoba» $(114,116)$.

\section{LO POLÍTICO Y LO FRÍVOLO}

Cuéntame cómo pasó es una serie que comienza a emitirse en 2001 con motivo del vigesimoquinto aniversario del comienzo a la Transición democrática. Por lo tanto, y a pesar de ofrecer una versión suavizada de la influencia de la política en la vida cotidiana, no deja de ser un texto revisionista del Franquismo (Estrada, 2004: 548).

Por lo tanto, en esta narración de la Transición, si bien mitificada y nostálgica, la serie no puede evitar «mojarse» en lo político. A pesar de esa aproximación amable $\mathrm{y}$ no vindicativa que ya han señalado varios autores (Brèmard, 2015; Estrada, 2004; Rueda y Guerra, 2009...), que hace del programa algo más bien lúdico, lo cierto es que lo político siempre se presenta como elemento de profundización en tramas más serias e, incluso, como hilo conductor de la maduración de los personajes (sobre todo de Toni, Inés y Carlos), o como presentación de estereotipos como el del «cura progre-catalán» encarnado en Eugenio y su gusto por Raimon, Lluis Llach o la canción tradicional en catalán (191-193, 195).

Y precisamente también por esto, lo político se presenta por oposición a lo frívolo. ¿Cómo se musicalizan ambos conceptos? Hay tres momentos en los que este enfrentamiento es evidente. El capítulo 9 (179-183) narra la historia de dos descubrimientos: el de las discotecas por parte de Inés y el de las protestas políticas estudiantiles por parte de Toni. Todo el capítulo es, en fin, una alternancia del primer contexto, el frívolo, y el segundo, el político. Otro caso es la noche de la muerte de Franco, un momento de gran trascendencia en el que Antonio y Mercedes acuden a ver una revista de Concha Velasco (198). Por último, destacamos la inauguración de la emisora de radio en el instituto de Carlos, que elige «Libertad sin Ira» como sintonía y en cuyo primer programa emiten una balada y, por error, «La Ramona» (199-201). 
Los tres hermanos pasarán por una fase despreocupada y otra marcada por el compromiso (en mayor o menor grado) con la búsqueda de un cambio político con respecto al régimen franquista. La fase frívola va a suponer en los tres casos su primera incursión en ambientes festivos. Así, Toni toca Los Payos en la guitarra con sus amigos o se imagina en un guateque amenizado por Los Bravos $(176,177)$. Inés descubre cuánto le gusta ir a la boîte a escuchar a Jimmy Fontana y Los Brincos $(179,181,183)$. Y Carlos se mete de lleno en la Movida madrileña tras pasar por David Bowie o Supertramp.

Sin embargo, esta fase frívola va a dar paso a diferentes caminos en cada uno de los hermanos. Toni será el que se implique más en la política, en su caso impulsado por su novia Marta, por quien cambia intereses y gustos. A partir de su encuentro, Toni sustituye los guateques del universitario despreocupado por un repertorio de cantautor, canción poética y canción protesta $(178,180,182$, 184-186, 188-190). Entre ellos, escucharemos repetidamente a Paco Ibáñez y, puntualmente, a Massiel, Luis Eduardo Aute, Joan Manuel Serrat, Lluis Llach y Atahualpa Yupanqui, un repertorio con el que también se encontrará Mercedes al entrar en la universidad (197) y que tenderá a desaparecer a medida que la acción de la serie se acerque a la década de los 80 .

Inés, por su parte, va a ser protagonista de un proceso de exploración mucho más variado y aparentemente menos relacionado con la política, aunque sí con su evolución como mujer disconforme con los roles de género que le han tocado (de sus gustos musicales ya hemos hablado en el apartado anterior). El proceso de Carlos es el único que se produce la inversa, ya que en su caso pasará primero por lo político al descubrir el comunismo (196) para, más adelante, pasar a formar parte de la juventud despreocupada de la Movida madrileña. Esto se muestra especialmente en el capítulo especial sobre la música de este movimiento, «La movida y mucho más» (episodio 234), que queda fuera de nuestro rango de análisis. En él Toni y Carlos muestran sus diferencias en gustos musicales. Carlos defiende que las letras de las canciones deben ser divertidas, mientras que para Toni «lo importante es que digan cosas».

Al margen de estas contraposiciones, otras canciones políticas aparecen de forma secundaria para ambientar momentos cotidianos, como la utilización de «La Internacional» en escenas románticas $(187,204)$, Toni cantando «Bella Ciao» mientras se ducha (202) o los coches con «Habla Pueblo, Habla» en la megafonía durante la campaña del referéndum de 1976 (203).

\section{CONCLUSIONES}

En este artículo hemos realizado un repaso de la forma en que la mirada actual de los medios audiovisuales traduce en música diversos conceptos contrapuestos 
de la España de la Transición a través de la serie más longeva de la televisión española: Cuéntame cómo pasó. Para ello hemos realizado un vaciado de música diegética de las 13 primeras temporadas. En los más de 200 ejemplos extraídos no están todos los que son, pero sí son todos los que están, habiéndose omitido la música con la que los personajes no interactúan directamente, aquellas piezas que no han podido ser reconocidas o las incluidas en los capítulos especiales 118 («Yesterday») y 234 («La Movida y mucho más»). Estos episodios resumen y justifican las elecciones musicales del resto y tienen un fin didáctico ya que, como indican Rueda y Guerra, la integración del pasado en la ficción en esta serie se resuelve con recursos diversos. Por ejemplo, cuando el acontecimiento externo presenta cierta magnitud (caso de la Movida) se produce «la interrupción del flujo ficcional mediante entregas de corte documental encaminadas a reafirmar el rango pedagógico de la serie mediante derivaciones de carácter explicativo sobre el contexto histórico» (2009: 404). De este modo, estos capítulos especiales recogen abundantes testimonios que hacen un repaso al panorama musical de los años $60-70$ y 80 , respectivamente.

Agrupando los repertorios extraídos se observa que se utilizan con funciones narrativa y descriptiva aludiendo a elementos contrapuestos pero complementarios. Así han aparecido varias categorías: grupos generacionales encarnados en abuelos y padres frente a los hijos; los entornos rural y urbano como contextos aislados y con estilos de vida opuestos; lo religioso y ritual frente a la celebración popular en guateques y verbenas, a veces eventos consecutivos; lo tradicional entendido como la educación recibida durante los años 40 y 50 frente a la modernidad aperturista del segundo franquismo; $y$, por último, el compromiso político frente a la «ceguera» voluntaria ante las tensiones sociales del momento.

La serie incluye numerosísimas cuñas musicales que, como decíamos, hemos agrupado en categorías que no son herméticas, sino en las que los repertorios fluyen de una a otra, de tal manera que Los Bravos nos pueden servir para ilustrar los gustos generacionales, el ambiente festivo de un guateque, la modernidad musical transmitida en locales de ocio o el carácter frívolo de un universitario despreocupado. De igual modo, unas rogativas a la Virgen se han incluido como repertorio vinculado al entorno rural, pero también habrían servido para caracterizar prácticas rituales. La clasificación de las piezas en una categoría u otra ha dependido del contexto en el que surgen.

Los estilos musicales van a tener mayor o menor continuidad y frecuencia de apariciones dependiendo de su asociación a una trama que justifique la música como elemento de identidad. De este modo, la canción protesta estará muy presente durante la primera temporada porque es en la que asistimos a la relación de Toni con Marta y a su descubrimiento de movimientos políticos clandestinos. Una vez que esta relación termine, la canción protesta desaparecerá progresivamente. Lo 
mismo ocurre con las tramas argumentales en las que Herminia acude al baile de mayores de la parroquia y Mercedes a clases de baile, en las que el pasodoble, el bolero y el cha-cha-chá estarán muy presentes. Uno de los personajes que más variedad dará en este sentido será Inés, una mujer inconformista que en su constante búsqueda nos llevará por distintos paisajes (el teatro, el cine, Gran Bretaña, Ibiza...) y, en cada una de estas aventuras, el repertorio será distinto.

Como uno de los productos estrella de Televisión Española, Cuéntame cómo pasó resulta ser para la música un medio de transmisión y actualización de repertorios teóricamente pasados de moda. Resultaría interesante explorar hasta qué punto este programa se ha constituido en rescatador y difusor de músicas obsoletas para el espectador más joven, y cómo a través de ellas se reconstruye la memoria sentimental y colectiva de una época (Rueda y Guerra, 2009: 402). Evidentemente, es la mirada actual la que va a delimitar mediante la música los espacios y significados de los que hemos venido hablando. Al fin y al cabo, en palabras de Pérez Borrajo, directores y guionistas «no solo son autoridades creativas, sino que son productores de significados con una capacidad de difusión masiva», por lo que no conviene olvidar «la agencia y capacidad que posee el elemento audiovisual a la hora de estandarizar y reforzar clichés socialmente aceptados» (2019: 146).

Por lo tanto, desde la perspectiva del emisor del mensaje ¿qué aprendemos los receptores sobre la España de los 70 y sus habitantes, tomando esta serie como fuente de información? La música nos dice que podemos identificar gustos generacionales compartidos entre abuelos y padres basados en la zarzuela, la copla, los bailes «agarraos» y, ya para los padres, la balada romántica y los bailes procedentes de ritmos americanos tropicales; estos chocan frontalmente con las preferencias de sus hijos, ya plenamente inmersos en las modas de las músicas populares urbanas (de las que la serie cubre un amplio espectro) y las adaptaciones que grupos españoles hacían de los estilos importados. Estos mismos repertorios sirven para caracterizar lo tradicional y lo moderno, aunque en esta ocasión no con un componente generacional sino ideológico, diferenciando a quienes apoyan o no protestan contra el Franquismo y quienes lo combaten activamente. En cambio, si las músicas populares urbanas sirven para representar la modernidad en algunos ámbitos, en otras ocasiones serán símbolo de lo frívolo por oposición a la canción protesta, que identificará a personajes claramente críticos con la dictadura. También en las prácticas rituales se percibirá la lucha entre modernidad y tradición, que en el ámbito eclesiástico se plasmará mediante prácticas musicales pre- y postconciliares, y en el entorno festivo incluirá un repertorio de amplio espectro al ser celebraciones intergeneracionales. Esta mirada desde el siglo XXI quiere incidir también en las diferencias abismales entre los modos de vida urbano y rural, y por eso dota al segundo de una ambientación basada en la música tradicional que poco a poco se irá abriendo a la llegada de 
otros repertorios traídos para satisfacer los gustos de la gente de la ciudad que de manera eventual se refugia en los pueblos.

Estos aprendizajes no dejan de ser resultado de una simplificación realizada por la mirada de directores y compositores y, a su vez, filtrada también por quien escribe estas líneas. Por lo tanto, quedaría un último paso que excede la extensión de este artículo, consistente en la corroboración de la veracidad de estas prácticas musicales, reflejadas en un producto de ficción treinta años después de que tuvieran lugar en la realidad. No obstante, estas caracterizaciones funcionan a priori de manera correcta, conectando con el espectador a través de la afectividad, lo que convierte las selecciones musicales en un artículo muy apetecible. Como indica Palacio (2006: 318), a estos productos televisivos se les deben aplicar meticulosamente las reglas de la mercadotecnia, y eso justifica la comercialización de varios recopilatorios musicales entre 2001 y 2013. La presentación de la serie como algo comercial, asequible a todos y desvinculada de una aproximación revisionista del Franquismo y la Transición, explicaría por qué estas colecciones se centran en la música más comercial para los consumidores jóvenes y música de baile para el espectador de más edad; y, en cambio, excluyen casi por completo los repertorios vinculados a los contextos ritual (música religiosa), rural (música tradicional), tradicional (zarzuela, copla y pasodoble) y político (canción protesta), que sí hemos incluido exhaustivamente en este estudio.

\section{BIBLIOGRAFÍA}

Barce, R. (1987). La ópera y la zarzuela en el siglo XIX. En España en la música de Occidente (vol. 2, pp. 145-153). Madrid: INAEM.

Brémard, B. (2015). La Transición, ¿un mito creado por y para la televisión?. Área Abierta, vol. ${ }^{\circ}$ 5, n. ${ }^{\circ}$ 3, 85-97. Disponible en: <https://revistas.ucm.es/index.php/ARAB/ article/view/48648/47272>.

Castillo Hinojosa, A. M.; Simelio Solà, N. y Ruiz Muñoz, M. J. (2012). La reconstrucción del pasado reciente a través de la narrativa televisiva. Estudio comparativo de los casos de Chile y España. Comunicación: Revista Internacional de Comunicación Audiovisual, Publicidad y Estudios Culturales, 666-681. Disponible en: <https:// idus.us.es/xmlui/bitstream/handle/11441/34496/Pages\%20from\%204-4.pdf?sequence $=1 \&$ is Allowed $=y>$.

Cruz Zamora, G. (2012). La música religiosa en las parroquias antes y después del Concilio Vaticano II. Revista Murciana de Antropología, n. ${ }^{\circ}$ 19, 117-128.

Diego, P.; Etayo, C. y Pardo, A. (2011). La percepción sobre la calidad de las series televisivas en España: contraste entre el público y los profesionales. Zer, vol. 16, n. ${ }^{\circ} 31$, pp. 69-88. 
JUDITH HELVIA GARCÍA MARTÍN

LA ESPAÑA DE LOS AÑOS 70 EN LA TELEVISIÓN CONTEMPORÁNEA. RECUERDOS DE UNA SOCIEDAD EN CONFLICTO A TRAVÉS DE LA MÚSICA EN CUÉNTAME CÓMO PASÓ

Domínguez Lázaro, M. ${ }^{a}$ R. (2010). La televisión en España, una visión retrospectiva tras la primera década del siglo XXI. Razón y Palabra, n. ${ }^{\circ}$ 71. Disponible en: <http:// www.razonypalabra.org.mx/N/N71/VARIA/24_REYES-REVISADO.pdf>.

Estrada, I. (2004). Cuéntame cómo pasó o la revisión televisiva de la historia española reciente. Hispanic Review, vol. 72, n. ${ }^{\circ}$ 4, 547-564.

García Lanciano, J. Música tradicional de la provincia de Albacete. Disponible en: <http:// www.dipualba.es/Publicaciones/Varias/Cds/Lanciano\%20n9\%20Vol.pdf> [Último acceso: 20/12/2014].

García Martín, J. H. (2015). ¿Qué nos cuenta la televisión? La historia de la música española en las series y su uso en el aula universitaria. En J. C. Montoya Rubio (Ed.), Didáctica a través de la canción popular y los medios audiovisuales. Nuevas perspectivas pedagógicas para la educación musical (pp. 153-174). Salamanca: Amarú Ediciones.

García Martín, J. H. (2016). La música tradicional en las producciones televisivas españolas y su recepción a través del streaming. En Sergio de Andrés Bailón (Ed.), Estudios sobre la influencia de la canción popular en el proceso de creación de música incidental (pp. 223-236). Salamanca: Ediciones Universidad de Salamanca.

Gómez, J. A. (2004). En la voz de nuestra música. Tópicos identitarios en la Etnomusicología española. Sulcum sevit: Estudios en homenaje a Eloy Benito Ruano. E. Benito Ruano (coord.), vol. 2, 973-1007.

González Lapuente, A. (2013). Historia de la música en España e Hispanoamérica 7. La música en España en el siglo XX. Madrid: Fondo de Cultura Económica de España.

Guillén Navarro, J. (2004). Introducción a la música tradicional de la provincia de Albacete. J. García Lanciano (Ed.). Zahora. Revista de Tradiciones Populares, 40, 15-55.

López, S. (2016). Mario de Benito. Componer para series de televisión: El hombre de tu vida. En J. A. Bornay Llinares, V. J. Ruiz Antón y J. Vera Guarinos (Coords, Pantallas pequeñas, ¿músicas menores? (pp. 181-200). Alicante: Letra de Palo.

López, S. (2016). Proceso creativo musical para una serie de televisión. Similitudes y diferencias con el cine. El caso de Mario de Benito. Creatividad y Sociedad. Creatividad y Cine, n. ${ }^{\circ}$ 25, 360-382. Disponible en: <http://www.creatividadysociedad. com/articulos/25/14. \% 20Proceso $\% 20$ creativo $\% 20$ musical $\% 20$ para $\% 20$ una $\% 20$ serie $\% 20$ de $\% 20$ television. $\% 20$ Similitudes $\% 20$ y 20 diferencias $\% 20$ con $\% 20$ el $\% 20$ cine. $\% 20 \mathrm{El} \% 20$ caso $\% 20 \mathrm{de} \% 20 \mathrm{Mario} \% 20 \mathrm{de} \% 20 \mathrm{Benito} . \mathrm{pdf}>$ [Última consulta: 25 de julio de 2019].

Mateos, J. (2014). La aportación de la televisión a la construcción del imaginario español. Comunicación y Medios, n. ${ }^{\circ}$ 29, 64-75. Disponible en: <https://comunicacionymedios. uchile.cl/index.php/RCM/article/view/30142/34124>.

Oller-Alonso, M. (2012). Nostalgic representation of reality in televisión fiction: an empirical study base don the analysis of the Spanish televisión series Cuéntame cómo pasó. Revista Mediterránea de Comunicación, vol. 3, n. ${ }^{\circ}$ 2, 128-142. Disponible en: $<$ https://rua.ua.es/dspace/bitstream/10045/23871/1/ReMedCom_03_12.pdf>.

Palacio Arranz, M. (2006). Cincuenta años de televisión en España. En José Fernández Beaumont (Coord.). Tendencias 06, Medios de comunicación: el año de la televisión (pp. 315-319). 
Pérez Borrajo, A. (2019). «La construcción de identidades a través de la pequeña pantalla. The Sopranos y la música popular italiana». Popular Music Research Today, 2, 133-147.

Piñeiro-Otero, T. (2018). Construcciones y transgresiones de la música en las series de ambientación histórica. Vivat Academia. Revista de Comunicación, n. ${ }^{\circ}$ 144, 144-110.

Rueda Laffond, J. C. y Guerra Gómez, A. (2009). Televisión y nostalgia. The Wonder Years y Cuéntame cómo pasó. Revista Latina de Comunicación Social, n. ${ }^{\circ}$ 64. Disponible en: <https://eprints.ucm.es/9806/1/Televisinostalgia.pdf>.

Romero Valiente, J. M. (2003). Migraciones. En Andrés Arroyo Pérez (Coord.), Tendencias demográficas durante el siglo XX en España (pp. 209-253).

Torrado Morales, S. y Castelo Blasco, C. (2005). Series de ficción de producción nacional y telespectadores: un negocio en bandeja. Comunicar, n. ${ }^{\circ} 25$. Disponible en: $<$ https:// www.revistacomunicar.com/verpdf.php?numero=25\&articulo=25-2005-097>.

\section{ANEXO}

En los ejemplos de músicas populares urbanas en los que no coincide la autoría de la canción con el grupo que lo interpreta, hemos incluido solo el segundo. De igual forma no incluimos autoría en ejemplos relativos a la música tradicional.

\section{Música clásica}

\begin{tabular}{|c|c|c|c|}
\hline N.o ej. & Capítulo & Minuto & Canción \\
\hline 1 & 82 & $00: 51: 50$ & Consagración de la Primavera (I. Stravinsky) \\
\hline 2 & 83 & $00: 09: 20$ & $\begin{array}{l}\text { Sonata para piano n. }{ }^{\circ} 11 \text {. Rondo alla Turca (W. } \\
\text { A. Mozart) }\end{array}$ \\
\hline 3 & & $00: 14: 00$ & $\begin{array}{l}\text { Concierto } \text { n. }^{\circ} 3 \text { en fa mayor. Allegro. (A. } \\
\text { Vivaldi) }\end{array}$ \\
\hline 4 & & $0: 39: 45$ & $\begin{array}{l}\text { Concierto n. }{ }^{\circ} 2 \text { en sol menor. Presto (A. } \\
\text { Vivaldi) }\end{array}$ \\
\hline 5 & & $00: 52: 00$ & $\begin{array}{l}\text { Concierto } \text { n. }^{\circ} 4 \text { en fa menor. Allegro non } \\
\text { molto (A. Vivaldi) }\end{array}$ \\
\hline 6 & & 01:02:31 & $\begin{array}{l}\text { Concierto n. }{ }^{\circ} 2 \text { en sol menor. Allegro non } \\
\text { molto. (A. Vivaldi) }\end{array}$ \\
\hline 7 & 85 & 01:06:10 & Para Elisa (L. V. Beethoven) \\
\hline 8 & 86 & $00: 44: 50$ & Para Elisa (L. V. Beethoven) \\
\hline
\end{tabular}


JUDITH HELVIA GARCÍA MARTÍN

LA ESPAÑA DE LOS AÑOS 70 EN LA TELEVISIÓN CONTEMPORÁNEA. RECUERDOS DE UNA SOCIEDAD EN CONFLICTO A TRAVÉS DE LA MÚSICA EN CUÉNTAME CÓMO PASÓ

\begin{tabular}{|c|c|c|l|}
\hline N. ${ }^{\circ}$ ej. & Capítulo & Minuto & \multicolumn{1}{c|}{ Canción } \\
\hline 9 & 104 & $00: 12: 12$ & $\begin{array}{l}\text { Concierto para clave n. }{ }^{\circ} 1 \text { en Re menor (J. S. } \\
\text { Bach) }\end{array}$ \\
\hline 10 & 133 & $01: 14: 05$ & $\begin{array}{l}\text { Música Acuática. Suite n. }{ }^{\circ} \text { 1 en Fa mayor, } \\
\text { Bourrée (G. F. Haendel) }\end{array}$ \\
\hline
\end{tabular}

Los abuelos, los padres, los nietos

\begin{tabular}{|c|c|c|c|}
\hline N. ${ }^{\circ}$ ej. & Capítulo & Minuto & Canción \\
\hline 11 & \multirow[t]{2}{*}{1} & $00: 06: 11$ & Toni quiere escuchar a Los Bravos en la radio \\
\hline 12 & & $00: 52: 30$ & La la lá (Massiel) \\
\hline 13 & 3 & $00: 29: 15$ & Black is Black (Los Bravos) \\
\hline 14 & 5 & 01:02:00 & La Bámbola (Patty Pravo) \\
\hline 15 & 7 & $00: 36: 34$ & Mejor (Los Brincos) \\
\hline 16 & 13 & $00: 55: 40$ & Toda una Vida (Antonio Machín) \\
\hline 17 & 17 & $00: 42: 30$ & Vivo Cantando (Salomé) \\
\hline 18 & 22 & $00: 29: 50$ & Adoro (Armando Manzanero) \\
\hline 19 & \multirow[t]{3}{*}{28} & $00: 55: 40$ & Mira que Eres linda (Antonio Machín) \\
\hline 20 & & $00: 59: 38$ & Esperanza (Antonio Machín) \\
\hline 21 & & $01: 02: 27$ & El Beso en España (Fernando Moraleda) \\
\hline 22 & 31 & $00: 26: 19$ & Dos Gardenias para ti (Antonio Machín) \\
\hline 23 & 38 & $00: 34: 38$ & Garufa (Carlos Gardel) \\
\hline 24 & 58 & $00: 41: 00$ & Perfidia (Luis Miguel) \\
\hline 25 & \multirow[t]{2}{*}{63} & $00: 38: 19$ & Solamente una Vez (Agustín Lara) \\
\hline 26 & & $00: 42: 53$ & Dos Gardenias para ti (Antonio Machín) \\
\hline 27 & 68 & $00: 53: 02$ & Padam Padam (Edith Piaf) \\
\hline 28 & 72 & $00: 59: 19$ & Buscando en el Baúl de los Recuerdos (Karina) \\
\hline
\end{tabular}

Ediciones Universidad de Salamanca / 
JUDITH HELVIA GARCÍA MARTÍN

LA ESPAÑA DE LOS AÑOS 70 EN LA TELEVISIÓN CONTEMPORÁNEA. RECUERDOS DE UNA SOCIEDAD EN CONFLICTO A TRAVÉS DE LA MÚSICA EN CUÉNTAME CÓMO PASÓ

\begin{tabular}{|c|c|c|c|}
\hline N. ${ }^{\circ}$ ej. & Capítulo & Minuto & Canción \\
\hline 29 & 73 & $00: 28: 30$ & $\begin{array}{l}\text { Antonio dice que le gustan los boleros y los } \\
\text { pasodobles }\end{array}$ \\
\hline 30 & 74 & $00: 39: 09$ & Buscando en el Baúl de los Recuerdos (Karina) \\
\hline 31 & \multirow[t]{3}{*}{82} & $00: 35: 58$ & Let the good Times Roll (The Animals) \\
\hline 32 & & $00: 37: 08$ & Bang a Gong/Get it on (T. Rex) \\
\hline 33 & & $00: 39: 00$ & Estoy bien/I Feel good (Los Impala) \\
\hline 34 & 83 & $00: 10: 04$ & $\begin{array}{l}\text { Mercedes dice que a Antonio le gustan los } \\
\text { boleros, el flamenco y la zarzuela }\end{array}$ \\
\hline 35 & 84 & $00: 40: 03$ & Ansiedad (Nat King Cole) \\
\hline 36 & \multirow[t]{3}{*}{125} & $00: 46: 41$ & Flamenco (Los Brincos) \\
\hline 37 & & $00: 51: 40$ & Por el Amor de una Mujer (Danny Daniel) \\
\hline 38 & & $00: 55: 10$ & Ay no Digas (Chris Montez) \\
\hline 39 & 171 & $00: 41: 49$ & $\begin{array}{l}\text { Johnny Hallyday, Benoît Blue Boy y Patrick } \\
\text { Verbeke }\end{array}$ \\
\hline 40 & 187 & 01:00:40 & Solamente una Vez (Agustín Lara) \\
\hline 41 & \multirow[t]{2}{*}{192} & $00: 22: 48$ & Si tú me Dices Ven (Los Panchos) \\
\hline 42 & & $00: 27: 40$ & Suspiros de España (Antonio Álvarez Alonso) \\
\hline 43 & 193 & 01:03:40 & Si tú me Dices Ven (Los Panchos) \\
\hline
\end{tabular}

Lo urbano y lo rural

\begin{tabular}{|c|c|c|l|}
\hline N. ${ }^{\text {ej. }}$ & Capítulo & Minuto & \multicolumn{1}{|c|}{ Canción } \\
\hline 44 & 8 & $00: 08: 40$ & La Cucaracha \\
\hline 45 & 54 & $00: 34: 17$ & Sorteo de Mayos \\
\cline { 3 - 4 } & & $01: 09: 20$ & iQué bonita te hizo Dios! (Julio Salgado) \\
\hline 46 & & $00: 06: 05$ & Nana \\
\hline 47 & 90 & \multicolumn{2}{|c}{} \\
\hline
\end{tabular}

Ediciones Universidad de Salamanca / ㅛ PopularMusicResearchToday,2,1(2020),pp.39-68 
JUDITH HELVIA GARCÍA MARTÍN

LA ESPAÑA DE LOS AÑOS 70 EN LA TELEVISIÓN CONTEMPORÁNEA. RECUERDOS DE UNA SOCIEDAD EN CONFLICTO A TRAVÉS DE LA MÚSICA EN CUÉNTAME CÓMO PASÓ

\begin{tabular}{|c|c|c|c|}
\hline N. ${ }^{o}$ ej. & Capítulo & Minuto & Canción \\
\hline 48 & 94 & $00: 13: 01$ & Para ser Conductor de primera \\
\hline 49 & 108 & $00: 43: 30$ & Vamos a Contar Mentiras \\
\hline 50 & \multirow[t]{3}{*}{115} & $00: 01: 27$ & Libre (Nino Bravo) \\
\hline 51 & & $00: 04: 00$ & $\begin{array}{l}\text { Romance de la Matanza (recogido por Nuevo } \\
\text { Mester de Juglaría) }\end{array}$ \\
\hline 52 & & $00: 35: 56$ & Rogativas a la Virgen de Turruchel \\
\hline 53 & \multirow[t]{5}{*}{124} & $00: 40: 00$ & A la Mancha manchega \\
\hline 54 & & $00: 57: 34$ & Una dola tela catola \\
\hline 55 & & 01:00:05 & Mambo n. ${ }^{\circ} 5$ (Dámaso Pérez Prado) \\
\hline 56 & & 01:04:04 & En er Mundo (Juan Quintero) \\
\hline 57 & & 01:09:27 & Luna de Miel (Gloria Lasso) \\
\hline 58 & 157 & $00: 30: 34$ & Nana \\
\hline 59 & 158 & $00: 01: 50$ & Quisiera Ser tan alta como la Luna \\
\hline 60 & 164 & $00: 38: 40$ & $\begin{array}{l}\text { Paquito el Chocolatero (Gustavo Pascual } \\
\text { Falcó) }\end{array}$ \\
\hline
\end{tabular}

Lo ritual y lo festivo

\begin{tabular}{|c|c|c|l|}
\hline N. ${ }^{\circ}$ ej. & Capítulo & Minuto & \multicolumn{1}{c|}{ Canción } \\
\hline 61 & 1 & $00: 17: 05$ & Órgano \\
\hline 62 & 6 & $00: 17: 34$ & Ave María de Fátima \\
\cline { 3 - 4 } & & $00: 19: 58$ & $\begin{array}{l}\text { Paquito el Chocolatero (Gustavo Pascual } \\
\text { Falcó) }\end{array}$ \\
\hline 63 & 40 & $01: 05: 23$ & $\begin{array}{l}\text { Paquito el Chocolatero (Gustavo Pascual } \\
\text { Falcó) }\end{array}$ \\
\hline
\end{tabular}

Ediciones Universidad de Salamanca / @्ब PopularMusicResearchToday,2,1(2020),pp.39-68 
JUDITH HELVIA GARCÍA MARTÍN

LA ESPAÑA DE LOS AÑOS 70 EN LA TELEVISIÓN CONTEMPORÁNEA. RECUERDOS DE UNA SOCIEDAD EN CONFLICTO A TRAVÉS DE LA MÚSICA EN CUÉNTAME CÓMO PASÓ

\begin{tabular}{|c|c|c|c|}
\hline N. ${ }^{\circ}$ ej. & Capítulo & Minuto & Canción \\
\hline 65 & \multirow[t]{2}{*}{46} & 01:09:51 & La Juventud Tiene Razón (Manolo Díaz) \\
\hline 66 & & $01: 13: 55$ & A la Huella a la Huella \\
\hline 67 & 47 & $00: 35: 30$ & Los Chicos con las Chicas (Los Bravos) \\
\hline 68 & 83 & $00: 50: 00$ & España Cañí (Pascual Marquina Narro) \\
\hline 69 & \multirow[t]{2}{*}{91} & $00: 55: 55$ & Black is Black (Los Bravos) \\
\hline 70 & & $00: 59: 02$ & Without you (Badfinger) \\
\hline 71 & 92 & $00: 06: 00$ & Adeste Fideles (himno popular) \\
\hline 72 & \multirow[t]{3}{*}{95} & $00: 44: 19$ & Marcha nupcial (F. Mendelssohn) \\
\hline 73 & & $00: 52: 08$ & Danubio azul (J. Strauss) \\
\hline 74 & & $00: 58: 00$ & $\begin{array}{l}\text { Paquito el Chocolatero (Gustavo Pascual } \\
\text { Falcó) }\end{array}$ \\
\hline 75 & 96 & $00: 56: 00$ & $\begin{array}{l}\text { ¡Qué Alegría cuando me Dijeron! (recogida en } \\
\text { el Cantoral Litúrgico Nacional) }\end{array}$ \\
\hline 76 & 116 & $01: 26: 25$ & Luna de Miel (Gloria Lasso) \\
\hline 77 & \multirow[t]{2}{*}{117} & $00: 41: 22$ & Twist Amor (Los Diablos Negros) \\
\hline 78 & & $00: 49: 00$ & Lola (Los Brincos) \\
\hline 79 & \multirow[t]{2}{*}{137} & $00: 03: 00$ & Fuga en Sol menor, BWV 535 (J. S. Bach) \\
\hline 80 & & $01: 02: 50$ & Panis Angelicus (C. Franck) \\
\hline 81 & 143 & $00: 29: 18$ & Aurresku \\
\hline 82 & \multirow[t]{2}{*}{144} & $00: 07: 00$ & ¡Oh Pecador! \\
\hline 83 & & 01:09:39 & I'm not in Love (10cc) \\
\hline 84 & \multirow[t]{3}{*}{146} & $00: 49: 20$ & Saca el Güiski, Cheli (Desmadre 75) \\
\hline 85 & & $00: 50: 30$ & El Jardín prohibido (Sandro Giacobbe) \\
\hline 86 & & $00: 54: 21$ & El Bimbó (Georgie Dann) \\
\hline
\end{tabular}


JUDITH HELVIA GARCÍA MARTÍN

LA ESPAÑA DE LOS AÑOS 70 EN LA TELEVISIÓN CONTEMPORÁNEA. RECUERDOS DE UNA SOCIEDAD EN CONFLICTO A TRAVÉS DE LA MÚSICA EN CUÉNTAME CÓMO PASÓ

\begin{tabular}{|c|c|c|c|}
\hline N. ${ }^{o}$ ej. & Capítulo & Minuto & Canción \\
\hline 87 & \multirow[t]{2}{*}{161} & $01: 15: 00$ & Guarda tus Besos para mí (Los Mismos) \\
\hline 88 & & $01: 17: 41$ & $\begin{array}{l}\text { Contigo en la Distancia (César Portillo de la } \\
\text { Luz) }\end{array}$ \\
\hline 89 & 163 & 01:08:02 & Tres veces guapa (Vicente Marí Bas) \\
\hline 90 & 167 & $00: 48: 28$ & Soul Singer (Steve Jeffries) \\
\hline 91 & 168 & $00: 58: 00$ & Fly, Robin Fly (Silver Convention) \\
\hline 92 & 171 & 01:07:40 & Yes Sir, I Can Boogie (Baccara) \\
\hline 93 & \multirow[t]{2}{*}{$182-183$} & $00: 05: 11$ & La Madrugá (Abel Moreno Gómez) \\
\hline 94 & & $00: 27: 00$ & Marcha Granadera \\
\hline 95 & \multirow[t]{2}{*}{191} & $01: 16: 55$ & El Bimbó (Georgie Dann) \\
\hline 96 & & $01: 19: 00$ & Quiero ser feliz (Rumba Tres) \\
\hline 97 & 193 & $01: 01: 17$ & Por tus Ojos negros (popular mexicana) \\
\hline 98 & \multirow[t]{2}{*}{198} & $00: 38: 50$ & $\begin{array}{l}\text { Qué Alegría cuando me Dijeron (recogida en } \\
\text { el Cantoral Litúrgico Nacional) }\end{array}$ \\
\hline 99 & & $00: 40: 41$ & Santo (contrafacta de Help, The Beatles) \\
\hline
\end{tabular}

\section{Lo tradicional y lo moderno}

\begin{tabular}{|c|c|c|l|}
\hline N. ${ }^{\circ}$ ej. & Capítulo & Minuto & \multicolumn{1}{c|}{ Canción } \\
\hline 100 & 1 & $00: 38: 21$ & Flamenca Yeyé (Carmen Sevilla) \\
\hline 101 & 3 & $00: 04: 47$ & Sol, Amor y Mar (Los Diablos) \\
\hline 102 & 4 & $00: 27: 58$ & Silvie Vartan \\
\cline { 1 - 1 } 103 & \multirow{2}{*}{$100: 29: 09$} & Black is Black (Los Bravos) \\
\cline { 1 - 1 } 104 & \multirow{2}{*}{16} & $00: 48: 10$ & La Vida Sigue igual (Julio Iglesias) \\
\hline 105 & & $\begin{array}{l}\text { Cántame un Pasodoble español (Tony } \\
\text { Leblanc) }\end{array}$ \\
\hline
\end{tabular}

Ediciones Universidad de Salamanca / 
JUDITH HELVIA GARCÍA MARTÍN

LA ESPAÑA DE LOS AÑOS 70 EN LA TELEVISIÓN CONTEMPORÁNEA. RECUERDOS DE UNA SOCIEDAD EN CONFLICTO A TRAVÉS DE LA MÚSICA EN CUÉNTAME CÓMO PASÓ

\begin{tabular}{|c|c|c|c|}
\hline N. ${ }^{o}$ ej. & Capítulo & Minuto & Canción \\
\hline 106 & 17 & $00: 34: 51$ & Chica Yeyé (Augusto Algueró) \\
\hline 107 & 18 & $00: 32: 09$ & Sunny (Bobby Hebb) \\
\hline 108 & 21 & $00: 10: 42$ & Casatschok (Georgie Dann) \\
\hline 109 & 25 & $00: 40: 00$ & $\begin{array}{l}\text { Paquito el Chocolatero (Gustavo Pascual } \\
\text { Falcó) }\end{array}$ \\
\hline 110 & 27 & $00: 08: 40$ & Let it $\mathrm{Be}$ (The Beatles) \\
\hline 111 & 29 & 01:09:52 & Te Vas a Enamorar (Palito Ortega) \\
\hline 112 & 41 & $00: 53: 46$ & Tete Montoliu \\
\hline 113 & 42 & $00: 52: 35$ & $\begin{array}{l}\text { Mami Llévame al Colegio/Las Leandras } \\
\text { (Francisco Alonso) }\end{array}$ \\
\hline 114 & \multirow[t]{3}{*}{44} & $00: 26: 38$ & Si yo Tuviera una Escoba (Los Sírex) \\
\hline 115 & & $00: 43: 30$ & Hey Baby (Madison) \\
\hline 116 & & $00: 52: 57$ & La Yenka (Johnny and Charley) \\
\hline 117 & 47 & $00: 46: 59$ & Romeo y Julieta (Karina) \\
\hline 118 & \multirow[t]{3}{*}{48} & $00: 21: 00$ & Shocking blue (Venus) \\
\hline 119 & & $00: 23: 57$ & Ma Vie, el Amor Conoció (Dyango) \\
\hline 120 & & $00: 38: 33$ & Dave Pike Set (Mathar) \\
\hline 121 & \multirow[t]{2}{*}{49} & $00: 19: 22$ & Los Chicos con las Chicas (Los Bravos) \\
\hline 122 & & $00: 19: 40$ & Tu Cabeza en mi Hombro (Enrique Guzmán) \\
\hline 123 & 50 & $00: 36: 01$ & Get on your Knees (Los Canarios) \\
\hline 124 & 51 & $00: 36: 28$ & Sympathy (Los Bravos) \\
\hline 125 & 52 & $00: 47: 12$ & Ne me Quitez pas (Jacques Brel) \\
\hline 126 & 57 & $00: 50: 20$ & Aline (Christophe) \\
\hline 127 & 59 & $00: 59: 33$ & El Gato montés (Manuel Penella Moreno) \\
\hline 128 & 60 & $00: 09: 16$ & Saint Tropez Twist (Lita Torelló) \\
\hline
\end{tabular}


JUDITH HELVIA GARCÍA MARTÍN

LA ESPAÑA DE LOS AÑOS 70 EN LA TELEVISIÓN CONTEMPORÁNEA. RECUERDOS DE UNA SOCIEDAD EN CONFLICTO A TRAVÉS DE LA MÚSICA EN CUÉNTAME CÓMO PASÓ

\begin{tabular}{|c|c|c|c|}
\hline N. ${ }^{\circ}$ ej. & Capítulo & Minuto & Canción \\
\hline 129 & 63 & $00: 40: 03$ & Rock de la Prisión (Bruno Lomas) \\
\hline 130 & \multirow{2}{*}{79} & $00: 53: 13$ & Amparito Roca (Jaume Teixidor Dalmau) \\
\hline 131 & & $00: 56: 22$ & La Cumparsita (Gerardo Matos) \\
\hline 132 & \multirow[t]{2}{*}{81} & $00: 46: 55$ & Estando contigo (Marisol) \\
\hline 133 & & $00: 50: 35$ & Tal Vez Mañana (Basilio) \\
\hline 134 & 96 & $01: 02: 13$ & Everybody’s Talking (Harry Nilsson) \\
\hline 135 & 98 & $00: 48: 29$ & Rock de la Prisión (Bruno Lomas) \\
\hline 136 & 102 & $00: 23: 11$ & Entre dos Aguas (Paco de Lucía) \\
\hline 137 & 104 & $00: 16: 20$ & The Sounds of Silence (Simon \& Garfunkel) \\
\hline 138 & \multirow{2}{*}{105} & $00: 29: 06$ & El Río (Miguel Ríos) \\
\hline 139 & & $00: 50: 58$ & Amor de Medianoche (Cecilia) \\
\hline 140 & 107 & $00: 25: 15$ & Yo Grito (Los Sírex) \\
\hline 141 & 109 & $0: 19: 20$ & Amor. Amar (Camilo Sesto) \\
\hline 142 & 109 & $00: 26: 05$ & Fresa Salvaje (Camilo Sesto) \\
\hline 143 & 114 & $00: 36: 53$ & A whiter Shade of Pale (Procol Harum) \\
\hline 144 & 120 & $00: 02: 27$ & Un Clavel (Rocío Jurado) \\
\hline 145 & 122 & $00: 27: 15$ & Nights in White Satin (Moody Blues) \\
\hline 146 & 124 & $00: 26: 08$ & Nights in White Satin (Moody Blues) \\
\hline 147 & 128 & $00: 52: 45$ & Una sencilla Canción de Amor (Tony Landa) \\
\hline 148 & \multirow[t]{3}{*}{130} & $00: 02: 01$ & Comunicando (Los 3 Carino) \\
\hline 149 & & $00: 32: 52$ & Kick Back (Liam Cooke) \\
\hline 150 & & $00: 34: 00$ & Pony Tail (Mo Foster) \\
\hline 151 & 135 & 01:00:08 & Mi gran Amor (Nino Bravo) \\
\hline 152 & 157 & $00: 14.06$ & Quando Dico di no (Raffaella Carrà) \\
\hline
\end{tabular}


JUDITH HELVIA GARCÍA MARTÍN

LA ESPAÑA DE LOS AÑOS 70 EN LA TELEVISIÓN CONTEMPORÁNEA. RECUERDOS DE UNA SOCIEDAD EN CONFLICTO A TRAVÉS DE LA MÚSICA EN CUÉNTAME CÓMO PASÓ

\begin{tabular}{|c|c|c|c|}
\hline N. ${ }^{\circ}$ ej. & Capítulo & Minuto & Canción \\
\hline 153 & 160 & $00: 48: 16$ & E tu (Claudio Baglioni) \\
\hline 154 & 161 & 00:07:01 & E tu (Claudio Baglioni) \\
\hline 155 & \multirow[t]{2}{*}{163} & $00: 09: 16$ & I Love to Love (Tina Charles) \\
\hline 156 & & $00: 40: 30$ & $\begin{array}{l}\text { Killing me softly with his Song (Roberta } \\
\text { Flack) }\end{array}$ \\
\hline 157 & \multirow[t]{2}{*}{167} & $00: 50: 20$ & Ni más ni menos (Los Chichos) \\
\hline 158 & & $00: 55: 30$ & Ansiedad (Nat King Cole) \\
\hline 159 & 171 & $00: 11: 46$ & $\begin{array}{l}\text { Killing me softly with his Song (Roberta } \\
\text { Flack) }\end{array}$ \\
\hline 160 & 174 & 01:06:10 & Fumando Espero (Juan Vidalomat) \\
\hline 161 & 176 & $00: 59: 38$ & I'm not in Love (10cc) \\
\hline 162 & 192 & $00: 23: 37$ & Love Is all (Alan Parker \& Madeline Bell) \\
\hline 163 & 194 & $00: 38: 50$ & Si Pudiera (Laurent Erdos) \\
\hline 164 & 197 & $00: 34: 12$ & Esto es Amor (Enrique y Ana) \\
\hline 165 & 201 & $00: 46: 29$ & Love is the Drug (Roxy Music) \\
\hline 166 & 203 & $00: 47: 02$ & Yes Sir, I Can Boogie (Baccara) \\
\hline 167 & \multirow[t]{2}{*}{206} & $00: 03: 58$ & Maneras de Vivir (Leño) \\
\hline 168 & & $00: 56: 58$ & Habanera del primer Amor (Vainica Doble) \\
\hline 169 & 207 & 00:09:29 & Baby, I Love your Way (Peter Frampton) \\
\hline 170 & 208 & $00: 21: 32$ & Colours (Donovan) \\
\hline 171 & 216 & $00: 13: 11$ & Para Hacer bien el Amor (Raffaella Carrà) \\
\hline 172 & 218 & $00: 59: 25$ & Para ti (Paraíso) \\
\hline 173 & 225 & $01: 16: 42$ & Héroes (David Bowie) \\
\hline 174 & 225 & 01:03:28 & Te Quiero, te Quiero (Nino Bravo) \\
\hline 175 & 226 & $00: 46: 50$ & Un Beso y una Flor (Nino Bravo) \\
\hline
\end{tabular}


JUDITH HELVIA GARCÍA MARTÍN

LA ESPAÑA DE LOS AÑOS 70 EN LA TELEVISIÓN CONTEMPORÁNEA. RECUERDOS DE UNA SOCIEDAD EN CONFLICTO A TRAVÉS DE LA MÚSICA EN CUÉNTAME CÓMO PASÓ

Lo político y lo frívolo

\begin{tabular}{|c|c|c|c|}
\hline N. ${ }^{\circ}$ ej. & Capítulo & Minuto & Canción \\
\hline 176 & 3 & $00: 39: 47$ & María Isabel (Los Payos) \\
\hline 177 & \multirow[t]{2}{*}{8} & $00: 18: 53$ & Black is Black (Los Bravos) \\
\hline 178 & & $00: 59: 40$ & Deja la Flor (Massiel) \\
\hline 179 & \multirow[t]{5}{*}{9} & $00: 15: 18$ & El Mundo (Jimmy Fontana) \\
\hline 180 & & $00: 17: 25$ & Aleluya n. ${ }^{\circ} 1$ (L. E. Aute) \\
\hline 181 & & $00: 27: 48$ & Flamenco (Los Brincos) \\
\hline 182 & & $01: 00: 25$ & Andaluces de Jaén (Paco Ibáñez) \\
\hline 183 & & 01:07:33 & La Motocicleta (Los Bravos) \\
\hline 184 & 10 & $00: 29: 45$ & El Poeta (Atahualpa Yupanqui) \\
\hline 185 & 11 & $00: 47: 20$ & $\begin{array}{l}\text { Déjame en Paz Amor tirano (versión Paco } \\
\text { Ibáñez) }\end{array}$ \\
\hline 186 & \multirow[t]{2}{*}{12} & $00: 34: 10$ & En la Plaza de mi Pueblo \\
\hline 187 & & $00: 36: 18$ & La Internacional \\
\hline 188 & 15 & 00:07:04 & España en Marcha (Paco Ibáñez) \\
\hline 189 & 16 & $00: 46: 16$ & Gracias a la Vida (Violeta Parra) \\
\hline 190 & 21 & $00: 21: 05$ & Me Queda la Palabra (Paco Ibáñez) \\
\hline 191 & 50 & $00: 12: 06$ & El Ball de la Civada (Joan Manuel Serrat) \\
\hline 192 & 52 & $00: 30: 26$ & La Barcelonista (Guillermina Motta) \\
\hline 193 & 61 & 01:04:15 & L'Estaca (Lluis Llach) \\
\hline 194 & 131 & 01:04:32 & La Internacional \\
\hline 195 & 138 & 01:08:31 & Diguem no (Raimon) \\
\hline 196 & 142 & $00: 03: 30$ & A las Barricadas (arreglo de Ángel Miret) \\
\hline 197 & 145 & $00: 19: 34$ & A Cántaros (Pablo Guerrero) \\
\hline
\end{tabular}


JUDITH HELVIA GARCÍA MARTÍN

LA ESPAÑA DE LOS AÑOS 70 EN LA TELEVISIÓN CONTEMPORÁNEA. RECUERDOS DE UNA SOCIEDAD EN CONFLICTO A TRAVÉS DE LA MÚSICA EN CUÉNTAME CÓMO PASÓ

\begin{tabular}{|c|c|c|l|}
\hline N. ${ }^{\text {ej. }}$ & Capítulo & Minuto & \multicolumn{1}{c|}{ Canción } \\
\hline 198 & 153 & $00: 14: 55$ & El Pichi (Francisco Alonso) \\
\hline 199 & 172 & $00: 56: 13$ & Libertad sin Ira (Jarcha) \\
\cline { 1 - 1 } 200 & & $00: 57: 00$ & La Ramona (Fernando Esteso) \\
\cline { 4 - 5 } 201 & & $00: 57: 28$ & We Shall Dance (Demis Roussos) \\
\hline 202 & 173 & $00: 08: 00$ & Bella ciao \\
\hline 203 & 175 & $00: 15: 06$ & Habla Pueblo Habla (Jarcha) \\
\hline 204 & 207 & $01: 04: 50$ & La Internacional \\
\hline
\end{tabular}

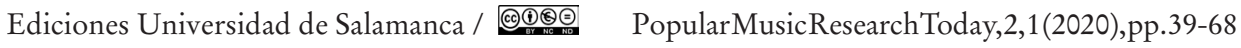

